\title{
Phytochemical and Antioxidant Activity in Seeds and Pulp of Grape Cultivated in Thailand
}

\author{
CHULEERAT WONGNARAT and PRASONG SRIHANAM* \\ Creative Chemistry and Innovation Research Unit, The Center of Excellence in Chemistry, \\ Department of Chemistry, Faculty of Science, Mahasarakham University, Kantarawichai, \\ Maha Sarakham 44150, Thailand. \\ ${ }^{*}$ Corresponding author E-mail: prasong.s@msu.ac.th \\ http://dx.doi.org/10.13005/ojc/330112 \\ (Received: November 07, 2016; Accepted: January 09, 2017)

\begin{abstract}
In this work, the seeds and pulp extracts of red and white grapes cultivated in Thailand had determined. The phenolic contents (total phenolic, flavonoid, proanthocyanidin and total saponin contents) were strongly positively correlated with the antioxidant activities which analyzed by different method (DPPH and ABTS radical-scavenging, FRAP and CUPRAC). The red grape seeds (RGS) showed the highest activity and polyphenol content among the sample types. According to the RP-HPLC analysis, the RGS had the highest catechin, epicatechin, myricetin, gallic acid, caffeic acid and ferulic acid levels. The obtained results confirmed that Thai grapes are a good source of phytochemicals and grape extracts should be developed as health supplement products.
\end{abstract}

Keywords: Antioxidant, phenolic content, correlation, source of phytochemical.

\section{INTRODUCTION}

Recently, the study of substances with protective effects against reactive oxygen and free radicals has attracted increasing attention. Several sources can produce free radicals that are both intraand extra-cellular ${ }^{1,2}$. Free radicals can cause the onset of oxidative stress, which can result in damage to biomolecules and chronic diseases ${ }^{3}$. Therefore, the interest in finding antioxidants has increased greatly, especially natural products. It is well known that plants, including vegetables, fruits, herbs and cereals, are the main sources of natural antioxidants. Plant antioxidants called "phytochemicals" have revealed potent efficiency against free radicals. Moreover, they also have various bioactivities, such as anti-inflammatory, antibacterial, anticancer, reduced risk of cardiovascular disease and diabetes ${ }^{4}$. Phenolic compounds in plants have been the subject of much study for their antioxidant 
properties ${ }^{5}$. Many studies have demonstrated that they significantly prevent some diseases, and reduce some effects of reactions ${ }^{6}$.

Grape is a fruit that is a rich source of phytochemicals. The phenolic compounds in grape are mainly distributed in different parts. Evidence of beneficial health effects from grape (Vitis sp.) and its products have been reported, especially for their cardio-protective action, treatment and prevention of cancer, antimicrobial activity and antiaging ${ }^{7-10}$. Grape is one of the most well-known fruits that is widely consumed in Thailand. It is easy to find fresh fruit that contains important vitamins, minerals and phytochemicals; however, information on the phytochemical properties of grape in Thailand is rare. Binit Shrestha et al. (2012) ${ }^{11}$ found that grape seed extract showed positive inhibitory effects with $S$. aureus at MIC of $0.625 \mathrm{mg} / \mathrm{mL}$ and MCC of 1.25 $\mathrm{mg} / \mathrm{mL}$ respectively. However the extracts showed minimal or no reactivity against strains of $E$. coli, K. pneumonia, C. parapsilosis and $C$. albicans. This is a newly report and only one article studied about grape by Thai researcher. In the present work, we characterized the phytochemicals and antioxidation in the seeds and pulp extracts of two grape (Vitis vinifera) cultivars cultivated in Thailand. The antioxidant activities of grape seed and pulp extracts, as well as the correlation coefficients between their phytochemical and antioxidant activities, were analyzed. The data related to the phytochemical and antioxidant capacity of the grapes consumed in Thailand are discussed.

\section{MATERIALS AND METHODS}

\section{Chemicals and reagents}

Pure standards of ferulic acid, caffeic acid, p-coumaric acid, myricetin, quercetin and resveratrol were purchased from Fisher Scientific (New Jersey, USA). The standards of aescin, vanillin, gallic acid, (+)-catechins, (-)-epicatechin, rutin, compounds 6-hydroxy-2,5,7,8-tetramethyl chroman-2-carboxylic acid (Trolox), 2,2-diphenyl-1-picrylhydrazyl (DPPH), 2,2'-azino-bis-3-ethylbenzothiazoline-6-sulphonic acid (ABTS), 2,4,6-tris (2-pyridyl)-S-triazine (TPTZ), Neocuproine (2,9-dimethyl-1,10-phenanthroline) and Folin-Ciocalteau's reagent were purchased from Sigma-Aldrich (USA). The organic solvents acetic acid, methanol and acetonitrile were of HPLC grade and purchased from Merck (Darmstadt, Germany) The other chemicals and solvents used were of analytical grade and were not further purify.

\section{Materials and sample preparation}

The red and white grapes (Vitis vinifera) were collected in October, 2015, from a local supermarket in Roi-Et Province, Thailand. They were washed to remove surface pollutants and manually separated into seeds and pulp. Grape seeds and pulp were dried ( $7-10 \%$ of moisture content) and ground using a mortar, and then stored at room temperature in desiccators until further analysis.

\section{Preparation of crude extract}

The $1 \mathrm{~g}$ of powdered seeds or pulp were weighed and mixed with $10 \mathrm{~mL}$ methanol under stirring for 3 hours. The extracted solutions were filtered and re-extracted three times using the same solvent and procedure. All of the extracts were then pooled, and centrifuged at $12,000 \mathrm{~g}$ for $30 \mathrm{~min}$ to remove the residue, and then the supernatant was filtered through filter paper (Whatman No. 1). The solvent was concentrated at $40^{\circ} \mathrm{C}$ by a rotary vacuum evaporator. The obtained crude extract was dissolved in methanol and stored in a freezer until analysis.

\section{Total phenolic content determination}

The total phenolic content (TPC) of the methanolic extract was determined following previous report ${ }^{12}$ with some modifications. A $200 \mu \mathrm{L}$ of the methanolic extract was mixed with $1.0 \mathrm{~mL}$ of $1: 10$ Folin-Ciocalteau reagent and $0.8 \mathrm{~mL}$ of $7.5 \% \mathrm{Na}_{2} \mathrm{CO}_{3}$ solution. The mixture solution was stand for $30 \mathrm{~min}$ before measured absorption at $765 \mathrm{~nm}$ by a UV-Vis spectrophotometer. The results were reported as $\mathrm{mg}$ GAE/g DW.

\section{Total flavonoid content determination}

The total flavonoid content (TFC) was determined following method described by Kubola and coworkers ${ }^{13}$. A $500 \mu \mathrm{L}$ of the methanolic extracts were added to $200 \mu \mathrm{L}$ of distilled water, and then $100 \mu \mathrm{L}$ of $5 \% \mathrm{NaNO}_{2}$ solution was added to the mixture. A $200 \mu \mathrm{L}$ of $10 \% \mathrm{AlCl}_{3}$ solution was added after $6 \mathrm{~min}$, and then stand for another $5 \mathrm{~min}$ before adding of $500 \mu \mathrm{L}$ of $1 \mathrm{M} \mathrm{NaOH}$ solution. After stirring and left to stand for $15 \mathrm{~min}$, the absorbance was measured by a UV-Vis spectrophotometer at $510 \mathrm{~nm}$. The results were reported as $\mathrm{mg} \mathrm{CE} / \mathrm{g} \mathrm{DW}$. 
Total proanthocyanidin content determination

The total proanthocyanidin content (TPAC) was analyzed via the procedure of $\mathrm{Li}$ and coworkers ${ }^{14}$ with some modifications. Each $200 \mu \mathrm{L}$ methanolic extract solution and $1.5 \mathrm{~mL}$ of $4 \%$ vanillinethanol solution was mixed together before adding $750 \mu \mathrm{L}$ concentrated $\mathrm{HCl}$. After left for $15 \mathrm{~min}$, the mixture was measured at $500 \mathrm{~nm}$ using a UV-Vis spectrophotometer. The results were reported as $\mathrm{mg} \mathrm{CE} / \mathrm{g}$ DW.

\section{Total saponin content determination}

The total saponin content (TSC) was determined following the method of Hiai and coworkers ${ }^{15}$. Briefly, A $250 \mu \mathrm{L}$ of standard solution or methanolic extracts $250 \mu \mathrm{L}$ of $8 \%$ vanillin-ethanol solution were mixed. A $2.5 \mathrm{~mL}$ of concentrated $\mathrm{H}_{2} \mathrm{SO}_{4}(72 \%)$ was then added with the mixture and stand in an ice water bath. The mixture solution was warmed at $60^{\circ} \mathrm{C}$ for $15 \mathrm{~min}$, and then cooled in ice-cold water to room temperature. The reaction mixture was measured at $560 \mathrm{~nm}$ using a UV-Vis spectrophotometer against a blank. The results were expressed as mg Aes/g DW.

\section{Determination of DPPH radical scavenging activity}

The DPPH' scavenging activity radicals of the methanolic extracts were determined according to a previously published method $^{16}$ with few modifications. An amount of $0.5 \mathrm{~mL}$ of diluted methanolic extract was added to $1 \mathrm{~mL}$ of freshly prepared $0.1 \mathrm{mM}$ DPPH in methanol solution and then incubated at room temperature in the dark for 30 min, the absorbance was detected at $517 \mathrm{~nm}$ using a UV-Vis spectrophotometer. The percent inhibition of the DPPH activity was calculated as:

$$
\text { DPPH inhibition }(\%)=\left[\left(A_{c}-A_{s}\right) / A_{c}\right] \times 100
$$

Where $A_{C}=$ absorbance of the control (blank) and $A_{S}=$ absorbance of the extract. The antioxidant activity represented via the $50 \%$ inhibition $\left(\mathrm{IC}_{50}\right)$ value.

\section{Determination of $\mathrm{ABTS}$ radical scavenging activity}

The ABTS radical scavenging activity of the methanolic extract was determined following the method as described previously ${ }^{17}$. A $7 \mathrm{mM} 2,2$ 'azino-bis(3-ethylbenothiazoline-6-sulfonic acid) diammonium salt (ABTS) was mixed with $2.45 \mathrm{mM}$ $\mathrm{K}_{2} \mathrm{~S}_{2} \mathrm{O}_{8}$ solution at the ratio of $1: 1$ to generate $A B T S^{++}$ and left to stand in dark for $16 \mathrm{~h}$ until the reaction was completed. The absorbance of $\mathrm{ABTS}^{*+}$ solution was adjusted by distilled water to $0.700 \pm 0.020$ at $734 \mathrm{~nm}$. The reaction between $0.5 \mathrm{~mL}$ of the diluted methanolic extract and $1 \mathrm{~mL}$ of $\mathrm{ABTS}^{*+}$ solution was performed and incubated at room temperature in the dark for 6 min before measuring at $734 \mathrm{~nm}$ using a UV-Vis spectrophotometer. The percent inhibition of $\mathrm{ABTS}^{*+}$ scavenging activity was calculated by following equation;

$$
\text { ABTS inhibition }(\%)=\left[\left(A_{c}-A_{s}\right) / A_{c}\right] \times 100
$$

Where $A_{C}=$ absorbance of the control (blank) and $A_{S}=$ absorbance of the extract. The antioxidant activity is represented by the $50 \%$ of inhibition $\left(\mathrm{IC}_{50}\right)$ value.

\section{Ferric reducing antioxidant power determination}

This reducing activity of the methanolic extract was determined by FRAP method described by $\mathrm{Li}$ and coworkers ${ }^{14}$ with slight modifications. To prepare the FRAP reagent, $1.5 \mathrm{~mL}$ of acetate buffer ( $\mathrm{pH} 3.6), 150 \mu \mathrm{L} 20 \mathrm{mM} \mathrm{FeCl}_{3}$ and $150 \mu \mathrm{L}$ $10 \mathrm{mM}$ TPTZ (2,4,6-tri(2-pyridyl)-s-triazine) in $40 \mathrm{mM} \mathrm{HCl}$ was mixed and warmed at $37^{\circ} \mathrm{C}$. A $150 \mu \mathrm{L}$ of methanolic extract was added to the mixture solution, and then incubated for $15 \mathrm{~min}$ at $37^{\circ} \mathrm{C}$. The absorbance of the mixture reaction was measured at $593 \mathrm{~nm}$ using a UV-Vis spectrophotometer. The results were expressed as $\mathrm{mmol} \mathrm{Fe}^{2+} / \mathrm{g} \mathrm{DW}$.

\section{Cupric reducing antioxidant capacity determination}

The cupric reducing antioxidant capacity (CUPRAC) was described by Apak and coworkers 18. A $500 \mu \mathrm{L}$ of $10^{-2} \mathrm{M} \mathrm{CuCl}_{2}$ solution was mixed with $500 \mu \mathrm{L} 7.5 \times 10^{-3} \mathrm{M}$ neocuproine solution in ethanol and acetate buffer at $\mathrm{pH}$ 7.0. The methanolic extract or standard $(\mathrm{x} \mu \mathrm{L})$ and $\mathrm{H}_{2} \mathrm{O}[(550-\mathrm{x}) \mu \mathrm{L}]$ were added to the mixture solution. The absorbance was recorded at $450 \mathrm{~nm}$ after incubation for $30 \mathrm{~min}$ at room temperature using a UV-Vis spectrophotometer. The results were expressed as $\mathrm{mg}$ TE/g DW. 
Identification and quantification of phenolic compounds using RP-HPLC

The RP-HPLC analysis with Shimadzu LC-20AC pumps (Shimadzu Co., Kyoto, Japan), SPD-M20A with a diode array detector and chromatographic separations were performed on a column Inetsil ODS-3, C18 (4.6 mm x $250 \mathrm{~mm}$, i.d. 5 ìm). The conditions used were followed Kubola and coworkers $^{13}$. The mobile phase are DI water with acetic acid ( $\mathrm{pH}$ 2.74) (solvent $A$ ) and acetonitrile (solvent B) were adjusted at a flow rate of 0.8 $\mathrm{mL} / \mathrm{min}$. The elution was performed by gradient system between solvent $A$ and solvent $B$ and a reequilibration period of $5 \mathrm{~min}$ with $5 \%$ solvent $B$ used between individual runs. The column temperature of $38{ }^{\circ} \mathrm{C}$ and $20 \mu \mathrm{L}$ injection volume were maintained. The spectra were recorded from 200 to $600 \mathrm{~nm}$ depending on each standard; Hydroxybenzoic acid $(280 \mathrm{~nm})$, hydroxycinnamic acid $(320 \mathrm{~nm})$, stilbene $(306 \mathrm{~nm})$ and flavonols $(360 \mathrm{~nm})$. Phenolic compounds were identified by comparing with those of external standard compounds.

\section{Statistical analysis}

All the assays were expressed as means \pm standard deviation (SD). Data analysis via the SPSS statistical software for Windows and one-way analysis of variance was done. The significance with $p<0.05$ by Duncan test was determined. Correlations of different assays were calculated using the correlation coefficient statistical option in the Pearson test.

\section{RESULTS AND DISCUSSIONS}

\section{Phytochemical contents}

The extraction yield and phytochemical contents in the grape pulp and seed extracts are presented in Table 1. The results showed different values for the mass amounts of the TPC, TFC, TPAC and TSC from the selected sample, as expected. The yields of all extraction varied from 12.77 to $83.60 \%$ $(w / w)$. The highest of extraction yield found in red grape pulp (RGP), then white grape pulp (WGP), white grape seed (WGS) and red grape seed (RGS) $(p<0.05)$, respectively.

Table 1 revealed the TPC values among the cultivars and parts. There were significant differences $(p<0.05)$ between the TPC values in the extracts from the cultivars. The TPC values of the grape seeds found from 151.56 to $481.25 \mathrm{mg} \mathrm{GAE} / \mathrm{g} \mathrm{DW}$, while in the grape pulp the values have 2.11 to $2.68 \mathrm{mg}$ GAE/g DW. The TPC in grape was, on average, 130fold more concentrated in the seeds than in the pulp. RGS (481.25 mg GAE/g DW) exhibited the highest value for the TPC followed by WGS, WGP and RGP. The values obtained in this work are higher than the results published by Anastasiadi and coworkers ${ }^{19}$, who studied the TPC in grape seeds (values ranged 820 to $3300 \mathrm{mg} / 100 \mathrm{~g}$ dry matter) and grape skins (values ranged 50 to $140 \mathrm{mg} / 100 \mathrm{~g}$ dry matter).

The TFC values of the extracts were calculated and are expressed in Table 1. The TFC was significantly $(p<0.05)$ higher in the seed than pulp extracts. The highest value for the TFC was found in the RGS (330.60 mg CE/g DW), which is about 2.5-fold higher than that of WGS (133.08 $\mathrm{mg} \mathrm{CE} / \mathrm{g} \mathrm{DW}$ ) and 300-fold higher than the pulps (averaging $1.08 \mathrm{mg} \mathrm{CE} / \mathrm{g} \mathrm{DW}$ ). This result agrees with a previous report that mentioned that grape seeds are richer in phenolic compounds than the grape pulp. This was due to the seeds acting as a reservoir for the development of the sprouts ${ }^{20}$.

The grape seed extracts also contained higher amounts of TPAC than the pulp extracts. Among them, RGS also had the highest amount of TPAC (99.43 mg CE/g DW), which was followed by WGS (38.21 mg CE/g DW), WGP (0.48 mg $\mathrm{CE} / \mathrm{g} \mathrm{DW}$ ) and RGP (0.33 $\mathrm{mg} \mathrm{CE} / \mathrm{g} \mathrm{DW})$. As suggested by Hernández-Jiménez and coworkers ${ }^{21}$, the major phenolic compounds in grape seeds are proanthocyanidins and they occur at higher levels than in other parts of the grapes. This demonstrate that grape seeds are a good source of proanthocyanidins that could be used as a novel therapeutic intervention against carcinogenesis ${ }^{22}$.

Table 1. showed the TSC values for the grape seed and pulp extracts are presented in The TSC value was significantly $(p<0.05)$ higher in the RGS (1094.12 $\mathrm{mg}$ Aes/g DW) than in the other samples, which were in the order of WGS $(609.52$ mg Aes/g DW), WGP (106.12 mg Aes/g DW) and RGP (102.86 mg Aes/g DW). Saponins are important secondary metabolites derived from various plants, and they have been used extensively in the drug-related industry due to their pharmaceutical 
properties. The saponin levels are different in individual parts of plants ${ }^{23}$.

\section{Antioxidant activities}

Table 2 presented antioxidant activities of the grape seed and pulp extracts which determined by DPPH, ABTS radical scavenging activity, ferric and cupric reducing antioxidant capacity.

We are well known that different methods to evaluate the antioxidant capacity to ensure reliable results are necessary ${ }^{24,25}$ according to different reaction characteristics and mechanisms. DPPH has been popularly applied for free radical scavenging assays Antioxidants can scavenge stable free DPPH radicals reduction reaction of electron hydrogen atom transfer ${ }^{24}$. The DPPH and ABTS assays were expressed as an $\mathrm{IC}_{50}$ value and compared to the trolox and ascorbic acid values (Table 2). The grape seed extracts on $\mathrm{DPPH}^{\circ}$ scavenging activity was higher than that of the grape pulp extracts. Among all of the methanolic extracts, RGS $\left(\mathrm{IC}_{50}=27.45\right.$ $\mu \mathrm{g} / \mathrm{mL})$ and RGP $\left(\mathrm{IC}_{50}=11631.96 \mu \mathrm{g} / \mathrm{mL}\right)$ exhibited the highest and lowest scavenging activities, respectively. The order of DPPH'scavenging activity was ascorbic acid $\mathrm{H} \approx$ trolox $\mathrm{H} \approx \mathrm{RGS} \mathrm{H} \approx$ WGS $>$ WGP $>$ RGP $(p<0.05)$. This revealed that the grape seed extracts (RGS and WGS) in this work have higher $\mathrm{DPPH}^{\circ}$ scavenging activities than the grape seed extracts (1.99 to $4.54 \mathrm{mg} / \mathrm{mL}$ ) reported by Farhadi and coworkers ${ }^{26}$.

The $\mathrm{ABTS}^{*+}$ scavenging activity was similar trend to the $\mathrm{DPPH}^{\cdot}$ scavenging results. The $\mathrm{IC}_{50}$ values of $\mathrm{ABTS}^{++}$scavenging activity were ascorbic acid $\mathrm{H} \approx$ trolox $\mathrm{H} \approx \mathrm{RGS} \mathrm{H} \approx$ WGS $>$ WGP $>\mathrm{RGP}(\mathrm{p}$ $<0.05$ ). Among the samples, RGS had the highest ABTS $^{\cdot+}$ scavenging activity $(16.4 \mu \mathrm{g} / \mathrm{mL})$ and RGP had the lowest activity $\left(\mathrm{IC}_{50}=4504.77 \mu \mathrm{g} / \mathrm{mL}\right)$. The lower $\mathrm{IC}_{50}$ values indicate higher radical scavenging activity. The results in the present work were in good agreement with Gengaihi and coworkers ${ }^{27}$ who

Table 1: Phytochemical content in grape pulp and seed extracts

\begin{tabular}{lccccc}
\hline Extract & Yield (\%) & $\begin{array}{c}\text { TPC } \\
\text { (mg GAE/g DW) }\end{array}$ & $\begin{array}{c}\text { TFC } \\
\text { (mg CE/g DW) }\end{array}$ & $\begin{array}{c}\text { TPAC } \\
\text { (mg CE/g DW) }\end{array}$ & $\begin{array}{c}\text { TSC } \\
\text { (mg Aes/g DW) }\end{array}$ \\
\hline WGP & $77.63 \pm 3.01^{\mathrm{b}}$ & $2.68 \pm 0.19^{\mathrm{c}}$ & $1.33 \pm 0.03^{\mathrm{c}}$ & $0.48 \pm 0.01^{\mathrm{c}}$ & $106.12 \pm 14.66^{\mathrm{c}}$ \\
RGP & $83.60 \pm 5.05^{\mathrm{a}}$ & $2.11 \pm 0.09^{\mathrm{c}}$ & $0.83 \pm 0.02^{\mathrm{c}}$ & $0.33 \pm 0.04^{\mathrm{c}}$ & $102.86 \pm 4.85^{\mathrm{c}}$ \\
WGS & $16.60 \pm 0.07^{\mathrm{c}}$ & $151.56 \pm 23.01^{\mathrm{b}}$ & $133.08 \pm 2.14^{\mathrm{b}}$ & $38.21 \pm 0.85^{\mathrm{b}}$ & $609.52 \pm 46.61^{\mathrm{b}}$ \\
RGS & $12.77 \pm 0.12^{\mathrm{d}}$ & $481.25 \pm 25.41^{\mathrm{a}}$ & $330.60 \pm 13.43^{\mathrm{a}}$ & $99.43 \pm 3.98^{\mathrm{a}}$ & $1094.12 \pm 67.27^{\mathrm{a}}$ \\
\hline
\end{tabular}

Different letters $(a, b, c)$ in the same column represent significant differences means at $p<0.05$. WGP, white grape pulp; RGP, red grape pulp; WGS, white grape seed; RGS, red grape seed

Table 2: Antioxidant activities of grape pulp and seed extracts

\begin{tabular}{|c|c|c|c|c|}
\hline Extract & $\mathrm{DPPH}^{\circ} \mathrm{IC}{ }_{50}(\mu \mathrm{g} / \mathrm{mL})$ & ABTS $^{\bullet+} \mathrm{IC}_{50}(\mu \mathrm{g} / \mathrm{mL})$ & $\begin{array}{c}\text { FRAP assay } \\
\left(\mu \mathrm{mol} \mathrm{Fe}^{2+} / \mathrm{g} \mathrm{DW}\right)\end{array}$ & $\begin{array}{c}\text { CUPRAC assay } \\
\text { (mg TE/g DW) }\end{array}$ \\
\hline WGP & $9280.19 \pm 16.28^{b}$ & $4446.26 \pm 88.06^{a}$ & $8.34 \pm 0.78^{c}$ & $1.49 \pm 0.10^{c}$ \\
\hline RGP & $11631.96 \pm 104.77^{a}$ & $4504.77 \pm 29.48^{a}$ & $5.58 \pm 0.51^{c}$ & $1.28 \pm 0.10^{c}$ \\
\hline WGS & $55.96 \pm 1.50^{c}$ & $42.67 \pm 1.50^{\mathrm{b}}$ & $663.79 \pm 77.14^{b}$ & $75.90 \pm 0.76^{b}$ \\
\hline RGS & $27.45 \pm 0.90^{\circ}$ & $16.40 \pm 0.34^{b}$ & $1753.03 \pm 42.27^{a}$ & $244.67 \pm 17.77^{a}$ \\
\hline Trolox ${ }^{* *}$ & $12.12 \pm 0.19^{c}$ & $12.78 \pm 0.25^{d}$ & - & - \\
\hline Ascorbic acid ${ }^{*}$ & $7.89 \pm 0.10^{c}$ & $8.911 \pm 0.42^{d}$ & - & - \\
\hline
\end{tabular}

${ }^{*}$ References synthetic antioxidants standard. Different letters in the same column represent significant differences means at $p<0.05$ 
found that grape seed extracts (20.2 to $21.6 \mu \mathrm{g} / \mathrm{mL}$ ) had higher $\mathrm{ABTS}^{\cdot+}$ scavenging activities than other samples (21.2 to $22.0 \mu \mathrm{g} / \mathrm{mL})$.

The FRAP and CUPRAC methods focus on reducing ability of the antioxidant on iron and copper ions. The results found that FRAP values of the RGS had the highest reducing power (1753.03 ìmol $\left.\mathrm{Fe}^{2+} / \mathrm{g} \mathrm{DW}\right)$, which was followed by WGS > WGP $\mathrm{H} \approx \mathrm{RGP}(p<0.05)$. The grape seed extracts showed higher FRAP values, which were about 173-fold (on average) higher than all the grape pulp extracts. Our results were the same report of Rockenbach and coworkers ${ }^{28}$ where the antioxidant activities of grape seed extracts (2942 to 21,492 ìmol $\mathrm{Fe}^{2+} / 100 \mathrm{~g}$ ) by FRAP assay were higher than the activities of other samples (1454 to $4362 \mu \mathrm{mol} \mathrm{Fe} \mathrm{F}^{2+} / 100 \mathrm{~g}$ ).

With the CUPRAC assay, the highest reducing ability was observed in the RGS (244.67 $\mathrm{mg} \mathrm{TE} / \mathrm{g} \mathrm{DW})$ among the other samples: WGS (75.90 $\mathrm{mg} \mathrm{TE} / \mathrm{g} \mathrm{DW})>$ WGP $(1.49 \mathrm{mg}$ TE/g DW) $\mathrm{H} \approx \mathrm{RGP}$ (1.28 $\mathrm{mg} \mathrm{TE} / \mathrm{g} \mathrm{DW})(p<0.05)$. Our results exhibited a higher CUPRAC value than that reported by Meng and coworkers ${ }^{25}$ (18.67 to $\left.34.77 \mu \mathrm{mol} \mathrm{TE} / \mathrm{g}\right)$.

The exogenous antioxidants, including total phenolic, flavonoids, proanthocyanidins and

Table 3: Correlation coefficients ( $r$ ) for relationships between phytochemical contents and different antioxidant assays

\begin{tabular}{lcccccccc}
\hline & TPC & TFC & TPAC & TSC & DPPH & ABTS ${ }^{*}$ & FRAP & CUPRAC \\
\hline TPC & 1 & $.990^{*}$ & $.996^{*}$ & $.973^{*}$ & $.978^{*}$ & $.996^{*}$ & $.981^{*}$ & $.982^{*}$ \\
TFC & - & 1 & $.997^{*}$ & $.991^{*}$ & $.995^{*}$ & $.998^{*}$ & $.993^{*}$ & $.982^{*}$ \\
TPAC & - & - & 1 & $.985^{*}$ & $.991^{*}$ & $1.000^{*}$ & $.992^{*}$ & $.981^{*}$ \\
TSC & - & - & - & 1 & $.998^{*}$ & $.987^{*}$ & $.996^{*}$ & $.970^{*}$ \\
DPPH & - & - & - & - & 1 & $.992^{*}$ & $.998^{*}$ & $.971^{*}$ \\
ABTS ${ }^{*}$ & - & - & - & - & - & 1 & $.993^{*}$ & $.981^{*}$ \\
FRAP & - & - & - & - & - & - & 1 & $.963^{*}$ \\
CUPRAC & - & - & - & - & - & - & - & 1 \\
\hline
\end{tabular}

${ }^{*}$ Correlation is significant at 0.01 level

Table 4: Composition and content of phenolic compound ( $\mathrm{mg} / \mathrm{g}$ dry weight) in grape pulp and seed extracts

\begin{tabular}{lcccc}
\hline & WGP & RGP & WGS & RGS \\
& & & & \\
Gallic acid & $0.44 \pm 0.06^{\mathrm{c}}$ & $0.37 \pm 0.05^{\mathrm{c}}$ & $1.11 \pm 0.00^{\mathrm{b}}$ & $2.76 \pm 0.03^{\mathrm{a}}$ \\
Caffeic acid & $0.04 \pm 0.00^{\mathrm{c}}$ & $0.03 \pm 0.00^{\mathrm{d}}$ & $0.22 \pm 0.01^{\mathrm{b}}$ & $0.25 \pm 0.11^{\mathrm{a}}$ \\
p-Coumaric acid & $0.01 \pm 0.00^{\mathrm{c}}$ & $0.01 \pm 0.00^{\mathrm{c}}$ & $0.09 \pm 0.00^{\mathrm{a}}$ & $0.06 \pm 0.00^{\mathrm{b}}$ \\
Ferulic acid & $0.01 \pm 0.00^{\mathrm{c}}$ & $0.01 \pm 0.00^{\mathrm{c}}$ & $0.09 \pm 0.00^{\mathrm{b}}$ & $0.13 \pm 0.03^{\mathrm{a}}$ \\
Resveratol & $\mathrm{ND}$ & $\mathrm{ND}$ & $0.07 \pm 0.01^{\mathrm{a}}$ & $0.02 \pm 0.00^{\mathrm{b}}$ \\
Catechin & $0.08 \pm 0.02^{\mathrm{c}}$ & $0.07 \pm 0.00^{\mathrm{c}}$ & $0.88 \pm 0.05^{\mathrm{b}}$ & $10.95 \pm 0.15^{\mathrm{a}}$ \\
Epicatechin & $0.05 \pm 0.01^{\mathrm{c}}$ & $0.05 \pm 0.00^{\mathrm{c}}$ & $0.78 \pm 0.04^{\mathrm{b}}$ & $6.78 \pm 0.20^{\mathrm{a}}$ \\
Rutin & $0.01 \pm 0.00^{\mathrm{b}}$ & $0.002 \pm 0.00^{\mathrm{c}}$ & $0.01 \pm 0.00^{\mathrm{b}}$ & $0.02 \pm 0.00^{\mathrm{a}}$ \\
Myricetin & $0.01 \pm 0.00^{\mathrm{c}}$ & $0.01 \pm 0.00^{\mathrm{c}}$ & $0.13 \pm 0.00^{\mathrm{b}}$ & $0.23 \pm 0.11^{\mathrm{a}}$ \\
Quercetin & $0.004 \pm 0.00^{\mathrm{b}}$ & $\mathrm{ND}$ & $0.01 \pm 0.00^{\mathrm{a}}$ & $\mathrm{ND}$ \\
Total & $0.65 \pm 0.07^{\mathrm{c}}$ & $0.56 \pm 0.05^{\mathrm{c}}$ & $3.38 \pm 0.09^{\mathrm{b}}$ & $21.21 \pm 0.40^{\mathrm{a}}$ \\
& & & & \\
\hline
\end{tabular}

Different letters in the same row represent significant differences mean at $p<0.05$. WGP, white grape pulp; RGP, red grape pulp; WGS, white grape seed; RGS, red grape seed. 
saponins, exhibit biological properties. Our results indicated similar patterns for the antioxidant activity analyzed by DPPH, ABTS, FRAP and CUPRAC assays. However, the values from each methods varied. The differences in the antioxidant activities of the extracts were affected by differences in the chemical structure, which possibly depends on the position of the $\mathrm{OH}$ group in combination with the adjacent double bond in the aromatic ring ${ }^{29}$.

\section{Correlation analysis}

Table 3 indicated correlation coefficients $(r)$ of the phytochemical contents and antioxidant activity by Pearson test. All of results were analyzed in the same table. The correlations among the TPC, TFC, TPAC and TSC in the seeds and pulp strongly suggested that the flavonoids, proanthocyanidins and saponins are the main compound of the total phenols in the grape seeds and pulp: the $r$-values ranged from 0.973 to $0.996(p<0.01)$. Strong positive correlation coefficients ( $r$-values ranged from 0.978 to $1.000, p$ $<0.01$ ) were observed between TPC, TFC, TPAC, TSC and antioxidant activities (DPPH', ABTS ${ }^{\circ}$, FRAP and CUPRAC assay). The results suggested that the phenolics, flavonoids, proanthocyanidins and saponins contents play an important role in the antioxidant activity in the grape seeds and pulp. A strong positive correlation between antioxidant activity and phenolic compounds of our results are in the same with other studies ${ }^{24,30,31}$.

\section{HPLC identification and quantification}

The individual phenolic contents in the grape pulp and seed extracts are presented in Table 4. They were identified by a direct comparison of their retention times with those of standards and calculated based on external calibration curves. The main phenolic compounds; caffeic acid, catechin, epicatechin, gallic acid, ferulic acid, myricetin, quercetin, $p$-coumaric acid, resveratol, and rutin were investigated. The results revealed that RGS exhibited the highest total value $(21.21 \mathrm{mg} / \mathrm{g})$, which was followed by WGS (3.38 mg/g), WGP $(0.65 \mathrm{mg} / \mathrm{g})$ and RGP $(0.56 \mathrm{mg} / \mathrm{g})$. Catechin and epicatechin were the predominant flavonoids in the seed extracts. The seed extracts had catechin (5.9 $\mathrm{mg} / \mathrm{g}$ on average) levels higher than the pulp (0.08 $\mathrm{mg} / \mathrm{g}$ on average) of about 73-fold. In addition, the seed extracts showed epicatechin contents of about $3.78 \mathrm{mg} / \mathrm{g}$ on average, which is about 75 -fold higher than the pulp extracts $(0.05 \mathrm{mg} / \mathrm{g}$ on average). RGS had the highest values of catechin $(10.95 \mathrm{mg} / \mathrm{g})$, epicatechin $(6.78 \mathrm{mg} / \mathrm{g})$ and total values, when compared to other substances. The HPLC result of the total proanthocyanidin in grape was similar to contents previously reported. Proanthocyanidins in the form of monomeric phenolic compounds, such as catechin and epicatechin, are rich in the grape seed extract ${ }^{32}$. Flavan-3-ol monomers, including epicatechin and catechin, are reported to be the major substances in grape seed. RGS had the highest flavonols contents (myricetin $(0.23 \mathrm{mg} / \mathrm{g})$ and rutin $(0.02 \mathrm{mg} / \mathrm{g}))$ of all extracts, which was followed by WGS, WGP and RGP. In contrast, quercetin was found only in the white grape extracts (WGS and WGP). The low flavonols content is in agreement with research by Burin and co-worker ${ }^{33}$, who found that $V$. vinifera and $V$. labrusca grapes had low concentrations of flavonol compounds. The flavonoids found in the grape seed about of $69.16 \%$ of the individual phenolics compounds for an average. This confirmed that flavonoids form the main type of the phenolics, which is in agree with the previous reports ${ }^{25,34}$. For resveratrols, the compound was found only in grape seed extracts (0.02 to 0.07 $\mathrm{mg} / \mathrm{g}$ ). Some literature reported that resveratrol was only found in grape skins ${ }^{17,35}$, which is contrary to our results. However, the results of the present work are in agreement with Ector and coworkers ${ }^{36}$, who reported that trans-resveratrol was contained in the seeds of Muscadine grapes at about $45 \mu \mathrm{g} / \mathrm{g}$. In the case of the phenolic acid contents, gallic acid was the predominant substance in the seed extract, and ranged from 1.11 to $2.76 \mathrm{mg} / \mathrm{g}$. The RGS had the highest values of gallic acid $(2.76 \mathrm{mg} / \mathrm{g})$, ferulic acid $(0.13 \mathrm{mg} / \mathrm{g})$ and caffeic acid $(0.25 \mathrm{mg} / \mathrm{g})$, which was followed by WGS, WGP and RGP. Various reports confirmed that the polyphenol composition of plants was affected by various factors, such as the cultivar, maturity, color, part of the fruit as well as genetics, climate, geographic origin, exposure to diseases and cultivation practices, which all act on the phytochemicals of plants ${ }^{37,38}$.

\section{CONCLUSION}

Our results indicate that the grape seed extracts have higher polyphenol contents than the pulp extracts. The RGS exhibited the highest phytochemical contents and antioxidant activity. It 
has equally effective activity compared to trolox and ascorbic acid by DPPH and ABTS assays. For HPLC analysis, catechin, caffeic acid, epicatechin, ferulic acid, gallic acid, rutin and myricetin are the main phenolic compounds in the RGS. In conclusion, RGS is a good potential natural source of antioxidants and might be further used as a food supplement for health benefits.

\section{ACKNOWLEDGEMENTS}

The authors would like to thank the Center of Excellence for Innovation in Chemistry $(\mathrm{PERCH}-$ $\mathrm{CIC})$, Commission on Higher Education, Ministry of Education, Thailand. We also thank the Office of the Higher Education Commission, Thailand for scholarship via the Human Resource Development in Science Project (Science Achievement Scholarship of Thailand; SAST) as well as research supporting scholarship for graduate student of Mahasarakham University for financial support.

\section{REFERENCES}

1. Carocho, M.; Ferreira, I. C. F. R. Food Chem. Toxicol. 2013, 51, 15.

2. Lobo, V.; Patil, A.; Phatak, A.; Chandra, N. Pharmacogn Rev. 2010, 4, 118.

3. Dalle-Donne, I.; Rossi, R.; Colombo, R.; Giustarini, D.; Milzani, A. Clinical Chem. 2006, $52,601$.

4. Laura, A.; Alvarez-Parrilla, E.; GonzálezAguilar, G. A. 2010. Fruit and vegetable phytochemicals. Massachusetts: WileyBlackwell.

5. Denev, P. N.; Kratchanov, C. G.; Ciz, M.; Lojek, A.; Kratchanova, M. G. Compr. Rev. Food. Sci. F. 2012, 11, 471.

6. Rodrigo, R.; Gil-Becerra, D. In Polyphenols in Human Health and Disease; Academic Press: San Diego, 2014, 201.

7. Anastasiadi, M.; Chorianopoulos, N. G.; Nychas, G. J.; Haroutounian, S. A. J. Agric. Food Chem. 2009, 57, 457.

8. Balu, M.; Sangeetha, P.; Murali, G.; Panneerselvam, C. Brain Res. Bull. 2006, 68,469

9. Hudson, T. S.; Hartle, D. K.; Hursting, S. D.; Nunez, N. P.; Wang, T. T.; Young, H. A.; Arany, P.; Green, J. E. Cancer Res. 2007, 67, 8396.

10. Shanmuganayagam, D.; Warner, T. F.; Krueger, C. G.; Reed, J. D.; Folts, J. D. Atherosclerosis 2007, 190, 135.

11. Binit Shrestha, M. L.; Srithavaj, T.; Sroisiri, T.; Boonyanit, T. Asian Pac J Trop Biomed. 2012, 2, 822.

12. Pastrana-Bonilla, E.; Akoh, C. C.; Sellappan, S.; Krewer, G. J. Agric. Food Chem. 2003, 51, 5497.
13. Kubola, J.; Siriamornpun, S.; Meeso, N. Food Chem. 2011, 126, 972.

14. Li, Y.; Guo, C.; Yang, J.; Wei, J.; Xu, J.; Cheng, S. Food Chem. 2006, 96, 254.

15. Hiai, S.; Oura, H.; Nakajima, T. Planta Med. 1976, 29, 116.

16. Choi, I. S.; Kwak, E. J. Food Sci. Biotechnol. 2014, 23, 1677.

17. Pastrana-Bonilla, E.; Akoh, C. C.; Sellappan, S.; Krewer, G. J. Agric. Food Chem. 2003, 51, 5497.

18. Apak, R.; Güçlü, K.; Özyürek, M.; Karademir, S. E. J. Agric. Food Chem. 2004, 52, 7970.

19. Anastasiadi, M.; Pratsinis, H.; Kletsas, D.; Skaltsounis, A.-L.; Haroutounian, S. A. Food Res. Int. 2010, 43, 805.

20. Pajak, P.; Socha, R.; Gałkowska, D.; Roznowski, , J.; Fortuna, T. Food Chem. 2014, 143, 300.

21. Hernández-Jiménez, A.; Gómez-Plaza, E.; Martínez-Cutillas, A.; Kennedy, J. A. J. Agric. Food Chem. 2009, 57, 10798.

22. Bagchi, D.; Swaroop, A.; Preuss, H. G.; Bagchi, M. Mutat. Res. 2014, 768, 69.

23. Cheok, C. Y.; Salman, H. A. K.; Sulaiman, R. Food Res. Int. 2014, 59, 16.

24. Kataliniæ, V.; Možina, S. S.; Skroza, D.; Generaliæ, I.; Abramoviè, H.; Miloš, M.; Ljubenkov, I.; Piskernik, S.; Pezo, I.; Terpinc, P.; Boban, M. Food Chem. 2010, 119, 715.

25. Meng, J. F.; Fang, Y. L.; Qin, M. Y.; Zhuang, X. F.; Zhang, Z. W. Food Chem. 2012, 134, 2049.

26. Farhadi, K.; Esmaeilzadeh, F.; Hatami, M.; Forough, M.; Molaie, R. Food Chem. 2016, 199, 847. 
27. Gengaihi, S. E.; Ella, F. M. A.; Ibrahim, A. Y.; Baker, D. H. A. Int. J. Pharm. Pharm. Sci. 2015 , 4, 212.

28. Rockenbach, I. I.; Gonzaga, L. V.; Rizelio, V. M.; Gonçalves, A. E. d. S. S.; Genovese, M. I.; Fett, R. Food Res. Int. 2011, 44, 897.

29. Ola, M. S.; Ahmed, M. M.; Ahmad, R.; Abuohashish, H. M.; Al-Rejaie, S. S.; Alhomida, A. S. J. Mol. Neurosci. 2015, 56, 440.

30. Guendez, R.; Kallithraka, S.; Makris, D. P.; Kefalas, P. Food Chem. 2005, 89, 1.

31. Meng, J.-F.; Fang, Y.-L.; Qin, M.-Y.; Zhuang, X.-F.; Zhang, Z.-W. Food Chem. 2012, 134, 2049.
32. Perumalla, A. V. S.; Hettiarachchy, N. S. Food Res. Int. 2011, 44, 827.

33. Burin, V. M.; Ferreira-Lima, N. E.; Panceri, C. P.; Bordignon-Luiz, M. T. Microchem. J. 2014, 114, 155.

34. Jiang, B.; Zhang, Z. W. Asian J. Chem. 2011, 23, 2558.

35. Yilmaz, Y.; Toledo, R. T. J. Agric. Food Chem. 2004, 52, 255.

36. Ector, B. J.; Magee, J. B.; Hegwood, C. P.; Coign, M. J. Am. J. Enol. Vitic. 1996, 47, 57.

37. Boonsod, Y.; Sangdee, A.; Srihanam, P. Br. J. Pharm. Res. 2014, 4, 23.

38. Bruno, G.; Sparapano, L. Physiol. Mol. Plant Pathol. 2007, 71, 210. 